\title{
Pathways towards coexistence with large carnivores in production systems
}

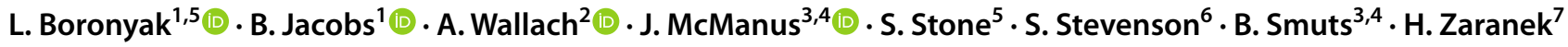

Accepted: 19 May 2021

( ) The Author(s), under exclusive licence to Springer Nature B.V. 2021

\begin{abstract}
Coexistence between livestock grazing and carnivores in rangelands is a major challenge in terms of sustainable agriculture, animal welfare, species conservation and ecosystem function. Many effective non-lethal tools exist to protect livestock from predation, yet their adoption remains limited. Using a social-ecological transformations framework, we present two qualitative models that depict transformative change in rangelands grazing. Developed through participatory processes with stakeholders from South Africa and the United States of America, the models articulate drivers of change and the essential pathways to transition from routine lethal management of carnivores towards mutually beneficial coexistence. The pathways define broad actions that incorporate multiple values in grazing systems including changes to livestock management practices, financial support, industry capacity building, research, improved governance and marketing initiatives. A key finding is the new concept of 'Predator Smart Farming', a holistic and conscientious approach to agriculture, which increases the resilience of landscapes, animals (domesticated and wild) and rural livelihoods. Implementation of these multiple pathways would lead to a future system that ensures thriving agricultural communities, secure livelihoods, reduced violence toward animals, and landscapes that are productive and support species conservation and coexistence.
\end{abstract}

Keywords Sustainable agriculture $\cdot$ Animal welfare $\cdot$ Human-wildlife coexistence $\cdot$ Extensive grazing $\cdot$ Social-Ecological Systems

L. Boronyak

Louise.Boronyak@uts.edu.au

B. Jacobs

Brent.Jacobs@uts.edu.au

A. Wallach

Arian.Wallach@uts.edu.au

1 Institute for Sustainable Futures, University of Technology Sydney, Sydney, Australia

2 Centre for Compassionate Conservation, University of Technology Sydney, Sydney, Australia

3 The Landmark Foundation, Western Cape, South Africa

4 Department of Biodiversity and Conservation Biology, University of the Western Cape, Cape Town, South Africa

5 International Wildlife Coexistence Network, Boise, Idaho, USA

6 Garden City, Idaho, USA

7 Tom Miner Basin, Helena, Montana, USA

\section{Introduction}

Human intolerance and persecution of large carnivores in production landscapes has deep historical and cultural roots (Woodroffe and Ginsberg 1998; Graham et al. 2005). Carnivore persecution not only presents a threat to lives of sentient beings, it also has been identified as a major constraint to conservation (Treves and Bruskotter 2014), to multi-species justice (Santiago-Ávila and Lynn 2020) and ecosystem health and function (Ripple et al. 2014). Carnivores are routinely killed to reduce predation on commercialised domestic animals in production systems such as sheep and cattle (hence 'livestock') (Ogada et al. 2003). However, evidence shows that killing carnivores often exacerbates livestock predation risk (see Berger 2006; McManus et al. 2015; Treves et al. 2016; Stone et al. 2017; Wallach et al. 2017; van Eeden et al. 2018a, b). Carnivore persecution is a key conservation concern as $77 \%$ of the world's largest carnivores are declining and $61 \%$ are threatened (Ripple et al. 2014). It has caused a contraction in large carnivore populations across their historical ranges (Ogada et al. 2003; Bergstrom 2017; 
Stone et al. 2017), and subsequent loss of predation as an ecosystem service (Beschta and Ripple 2009). Carnivore persecution may also disrupt other ecosystem services that underpin agricultural production, such as primary productivity, nutrient cycling, soil richness, and pollination (Fischer et al. 2006; Naidoo et al. 2008; Beschta and Ripple 2009; Estes et al. 2011; Cardinale et al. 2012). Indeed, advances in conservation have demonstrated the importance of large carnivores in the maintenance of ecosystem health and function (Ripple et al. 2014).

Given the threats presented by persecution, there are increasing calls for acceptance and tolerance of carnivores in production landscapes (Manfredo et al. 2009; Treves and Bruskotter 2014; Johnson and Wallach 2016; Stone et al. 2017). These recommendations are part of wider calls for adopting models of sustainability across all human activities (Gunderson and Holling 2002; Folke et al. 2005; Abson et al. 2017; Sellberg et al. 2017). Wildlife friendly farming has been advocated as a model of sustainable farming that better balances agricultural and conservation interests (Green et al. 2005; Fischer et al. 2008; White 2012; Johnson and Wallach 2016). It values the use of preventive non-lethal innovations, which include various proactive and preventive practices and tools that aim to reduce the vulnerability of livestock to predation by minimizing encounters between livestock and carnivores (Stone et al. 2017; Boronyak et al. 2020). Wildlife friendly farming is a global farming movement in which wildlife are tolerated and protected in production landscapes (Johnson and Wallach 2016). Tolerance of wildlife involves an acceptance of the real and perceived costs and benefits of living alongside them (Bruskotter and Fulton 2012; Kansky et al. 2016).

Coexistence with carnivores requires fundamental system transformation because the current system prioritizes agricultural-financial interests over biodiversity conservation and is entrenched in lethal methods that significantly impact the persistence and welfare of carnivores (Bergstrom et al. 2014). Transformation represents fundamental changes across multiple systems: socio-cultural, political, economic and technological, resulting in the creation of a 'new system' (Van Den Bergh et al. 2011; Rickards and Howden 2012; Patterson et al. 2015). Transformations towards sustainability entail planned transitions and have been considered across a diverse range of issues including energy (van Vuuren et al. 2012), water (Pahl-Wostl 2002), agriculture (Rickards and Howden 2012; Gosnell et al. 2019) and cross cutting issues such as climate change (Abson et al. 2017; O'Brien 2018).

To explore pathways toward transformation in rangeland grazing systems we draw on Sellberg et al.'s (2017) integrative framework. This framework enhances a placebased understanding of ecological resilience and complex systems while also articulating various pathways that foster transformations towards global sustainability (Sellberg et al. 2017). Sellberg's framework integrates concepts of socialecological resilience (maintenance of critical ecosystem services and avoidance of ecosystem degradation or collapse) (The Resilience Alliance 2010) with socio-technical transition theory that describes niche innovations and their interactions with existing social-technical regimes (Geels and Schot 2007). A social-ecological systems (SES) approach is useful in understanding the interplay of social, environmental and economic factors that drive human-wildlife conflict (Waudby et al. 2020). This approach also identifies interventions to move beyond maintaining business-as-usual practices towards the local-regional scale transformations, which this paper focuses on as human-carnivore coexistence. Coexistence has an explicit spatial-temporal-ecological dimension that implies species living together in the same landscape at the same time (Marchini et al. 2019). Yet it also has a relational dimension as it encompasses how people relate to and live alongside wildlife in ways that are peaceful and mutually beneficial (Marchini et al. 2019).

We present the results from a series of participatory engagement processes with key stakeholders to develop models of transformative change for rangeland grazing in South Africa and the United States (USA). We focused on commercial livestock production in South Africa and the USA to provide related but distinct case studies on the challenge of coexistence between humans and large carnivores in social-ecological systems, such as rangelands. We chose these countries because they encompass large areas broadly defined as rangelands (United States: $31 \%$ of 11 states land areas; South Africa: $91 \%$ of the land area) that are used extensively for livestock grazing (Havstad et al. 2007; Goldblatt 2011; Palmer and Bennett 2013); and are inhabited by diverse array of large carnivores (Carnivora species with body mass $>10 \mathrm{~kg}$; hence carnivores); and have a long history of carnivore persecution livestock producers (hence producers). Large carnivores such as leopard (Panthera pardus) are still prevalent in South Africa's rangelands (Swanepoel et al. 2013). In the USA, coyotes are common rangeland predators, and increasingly wolf (C. lupus), bear (Ursus spp.), and cougar (Puma concolor) as populations are recovering in rangelands (Schwartz et al. 2001; Kendall et al. 2009; Maletzke et al. 2016; Gigliotti et al. 2019).

The models developed in this study describe four key components (Jacobs et al. 2017): (1) the current dominant functioning of the system (business-as-usual); (2) the drivers of change that exert pressure on business-as-usual and determine the extent and direction of change within the system; (3) the vision and characteristics of a 'desired' future (the 'transformed system') that incorporates multiple values, and (4) transition pathways as a continuous processes of change along a range of possible development paths that emerge from individual and collective actions, and which 
deviate from what is considered the norm. These multiple pathways provide a bridge to the transformed system and act to reinforce each other to create transformative change. Pathways approaches call for adaptive, context-specific actions to address sustainability challenges and also recognise that there are multiple alternatives or pathways towards socio-ecological sustainability (Cockburn et al. 2018) and therefore provide a solid frame to explore human-carnivore coexistence.

\section{Methods}

Norström et al. (2020) defined four principles for knowledge co-production within the field of sustainability research as being context-based, pluralistic, goal-orientated and interactive. We employed these co-production principles to gather the information needed to develop the change models. The research was situated in the context of rangeland grazing systems in two countries, it engaged interactively with multiple knowledge sources (e.g. academic and informal) from diverse stakeholders with the explicit goal of transforming current management practices in each country (Djenontin and Meadow 2018). For South Africa, the change model was developed through multiple engagements, initially in a workshop with livestock producers, conservationists, experts and practitioners at the Pathways to Coexistence Conference in Namibia in 2018. A model template (Fig. 1) was used to guide discussions and elicit information from 40 workshop participants on the topic of human-carnivore conflicts in extensive rangelands grazing in Africa. The participants provided information that was used to populate the four components of the template (i.e. drivers of change, business-asusual, transition pathways and the transformed system) and presented a model of transformative change (Jacobs et al. 2017). The models are not intended to depict mechanistic relationships between components because, for example, a single pathway is unlikely to directly connect single attributes of the current system state with those of the transformed system. The template is based on a modified 'three-horizons' approach used in futures work that connects the present with visioning divergent futures based on a set of values (Curry and Hodgson 2008). The timescale, determined through stakeholder deliberation at the workshop, starts when the stakeholders were first engaged in 2018 and ends with a future system in the year 2040 in recognition of the likely extended timescales required to realistically achieve transformation in an SES.

Information from the workshop was supplemented, verified and refined for the South African context through semi-structured interviews with 16 livestock producers, two conservation non-government organizations (NGOs), and two government representatives (20 individuals in total). The interviews occurred in three provinces in South Africa including the Eastern and Western Cape and the Free State. We used a purposive sampling procedure (Bryant and Charmaz 2010) to identify key stakeholders that possessed specialist knowledge in livestock production,

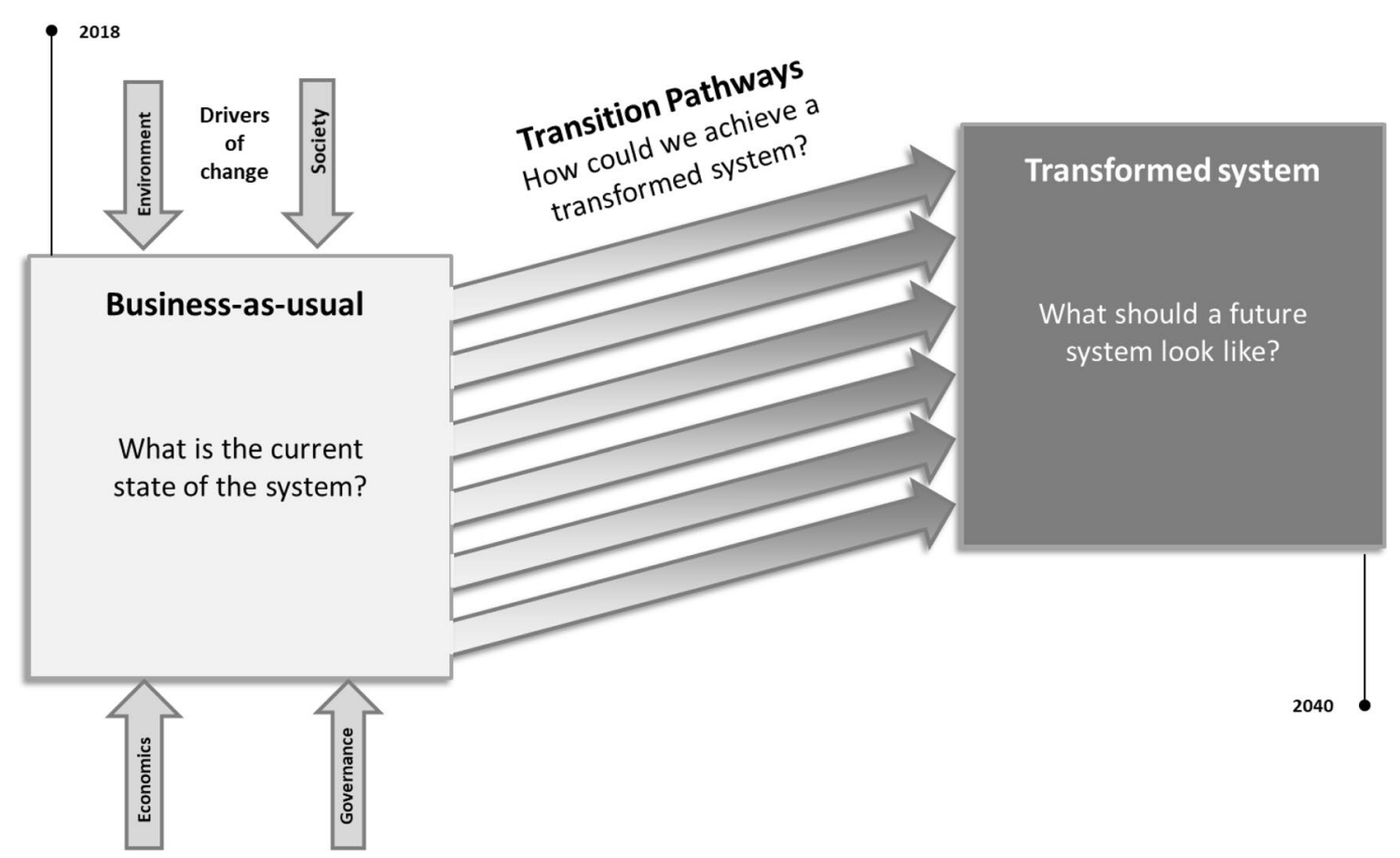

Fig. 1 A conceptual model of transformation for extensive grazing of rangeland systems ( Adapted from Jacobs et al. 2016) 
human-carnivore interactions in rangelands grazing and the capacity to mitigate predation risk in livestock grazing. Initially, stakeholders were recruited via existing contacts with environmental NGOs in South Africa and the USA. At the conclusion of each interview, we asked each interviewee to recommend additional producers. This snowball sampling method increased the sample size, broadened the extent of viewpoints canvased (to include users of lethal and nonlethal carnivore management practices) and ensured theoretical saturation or the point in data collection and analysis when new incoming data produces little or no new information to address the research questions (Glasser and Strauss 2009). In the USA in total 16 commercial producers were interviewed with 12 relying primarily on non-lethal tools and approaches (herein non-lethal producers) and four relying on lethal approaches to manage predation risk (herein lethal producers). Similarly, in South Africa 16 commercial producers were interviewed, with the sample comprising nine non-lethal producers and seven that used lethal management practices. The semi-structured interviews were conducted in person and averaged between $60-90 \mathrm{~min}$. All of the stakeholders that participated in a workshop or interview were provided with an information sheet outlining the scope of the research and provided informed consent to participate in the research. Human research ethics approval was granted by the University of Technology Sydney (ETH18-2568HREC). During analysis qualitative data were synthesised and anonymised.

The interviews commenced with participants introducing themselves and giving an overview of their livestock operation or role in government or NGO and their interactions with carnivores. Specifically, producers were asked about the impacts of predation on their business, and all stakeholders were asked about their preferred approaches to mitigating predation (i.e., lethal or non-lethal to carnivores), their perceived effectiveness of each mitigation approach, landscape management, and the available supports and incentives to adopt preventive non-lethal innovations (herein preventive innovations) (e.g. Pannell and Vanclay 2011; Boronyak et al. 2020). Interviews concluded with participants' envisioning the possible or preferred future in the year 2040 .

The model for rangelands grazing in the western USA was developed from information gathered during semi-structured interviews conducted between 2018 and 2019 with representatives from California, Idaho, Oregon, and Montana. The same participant recruitment and interview process was followed in South Africa. Interviews were conducted with 16 livestock producers, six former and current representatives from government wildlife agencies, and 3 conservation NGOs (25 individuals in total). Information from the interviews was supplemented with lessons from the Defenders of Wildlife Coexistence conference October 2019. With the participants' consent, all interviews in both countries were audio recorded, transcribed verbatim and analyzed using MAXQDA software (VERBI GmbH version 18.2.0). The transcripts were coded line-by-line (Saldana 2009) into categories that corresponded to the four components of the model. The information was collated, synthesized and then transferred to the model template.

As the USA model was collated from information gathered by interviews only, it was validated using a modified Delphi approach. The Delphi approach seeks to ensure accuracy, reach a consensus, and check for omissions or misinterpretation but not alter content provided in the original engagement process (Mead and Moseley 2001) by drawing on diverse knowledge and experiences of a range of experts (Powell 2002). The draft model was sent to 10 of the interviewees representing a mix of livestock production, conservation and governance to elicit feedback. Feedback was received through three rounds of comments from seven participants in total: five participants in rounds one and two, and two participants in round three. At each round, the model was revised, comments anonymized and returned to the original ten participants. The model was finalized when consensus was achieved among the experts.

\section{Results}

\section{The South African model}

The information gathered through engagement with stakeholders was synthesised into a model of transformative change in South African extensive grazing systems (Fig. 2).

\section{System drivers}

Participants discussed a range of drivers of change that act on extensive rangelands grazing systems in South Africa. Representatives from environmental NGOs recognized South Africa's rich biological diversity, however land use change and overgrazing due to agriculture, as well as the impacts from mining and urbanisation were viewed as contributing to the loss and degradation of natural habitat, soils and biodiversity. In South Africa, 69\% of the land surface is suited to livestock grazing yet grasslands are one of the country's most threatened biomes (Goldblatt 2011) due to growing pressure to maximize productivity to feed a growing human population. Similarly, wildlife faces pressure from both consumptive use, such as hunting on private game farms, and non-consumptive use through eco-tourism activities on private game reserves, national parks and other protected areas. Workshop participants noted that local community values and perceptions of carnivores influence their treatment. For example, leopards appear to have a high perceived value (i.e., high aesthetic, conservation or tourism 


\section{SYSTEM DRIVERS}

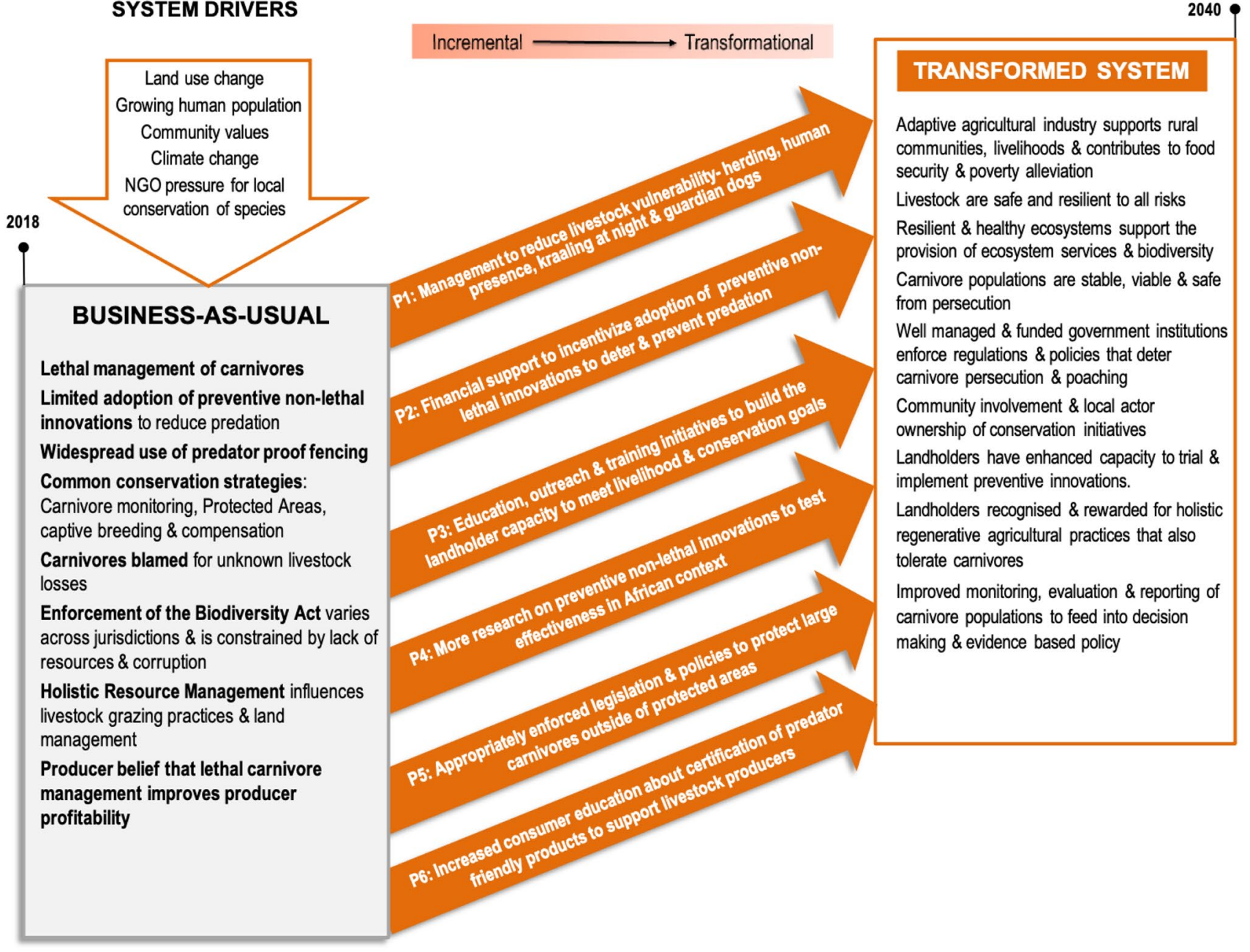

Fig. 2 A model of transformative change in extensive grazing systems in South Africa. Pathways are numbered P1 to P6

value) and were tolerated more other carnivores such as a black-backed jackal yet it remains unclear how any financial benefits from leopards are shared with local communities. Lastly, the impacts of climate change in the form of changing rainfall patterns and extended drought are exacerbating groundcover loss, particularly in grazed arid rangelands, affecting long-term soil health and water retention. Loss of forage was identified as affecting the nutrition and health of domesticated livestock making them more vulnerable to predation, which can heighten on-going human-carnivore conflict.

The producers who predominantly used lethal control appeared to have negative attitudes towards carnivores, predominantly black-backed jackals and caracal. They perceived these species as 'vermin' to be eradicated. These views were driving the increasing militarisation of carnivore control with the use of night vision glasses, devices that mimicked the vocalisations of carnivores (referred to as night callers), modification of vehicle seating to facilitate use of firearms, as well as community organised and funded ground and aerial shooting from a helicopter. This has culminated in a high degree of social pressure to continue to persecute carnivores, the cost of which is borne by individual landholders. In seeking to counter the trend of ecosystem degradation and carnivore persecution, local and international NGOs are pushing to protect carnivores outside protected areas and demonstrate that holistic models of coexistence that preserve natural resources (soils, habitat and biodiversity) can be economically viable.

\section{Current system}

Business-as-usual in South African extensive grazing systems was characterized by the continued persecution of leopard, caracal, and black-backed jackal. Producers reported that carnivore persecution on individual farms was undertaken by staff or private contractors using shooting, trapping and hunting with dogs. Some lethal producers reported using 
poisons (e.g., Temik and Sodium fluoroacetate) despite the un-licensed use of poison against wildlife being legally prohibited in South Africa.

The use of preventive non-lethal innovations appeared to be ad hoc and limited, with the most widely reported strategy used by producers being permanent predator-proof or temporary electric fencing. Workshop participants that identified themselves as conservation researchers noted that permanent fencing impedes the movement of wildlife and poses a danger of entanglement. Non-lethal producers reported success using guardian animals (i.e., livestock guardian dogs and alpacas) and guardian humans to reduce theft and predation. Producers recognized that livestock herding and guarding by humans is effective at reducing predation yet had reservations about the cost of hiring and managing extra staff. Producers instead installed electric fencing despite its high cost and limitations from shorting-out from vegetation or damage from wildlife. Some producers had adopted preventive innovations (e.g., deterrents such as flashing lights or sounds or livestock protection collars to prevent carnivores biting livestock around the neck). Several producers mentioned the influence of 'holistic resource management' and its variants on their grazing practices. Holistic resource management involves high-density short-duration grazing followed by an extended rest period for the land with no grazing. Producers using holistic resource management noted various landscape benefits such as mechanical soil disturbance and nutrient cycling allowing for greater water infiltration and improved plant growth and diversity after rainfall compared with lower density set-stocking.

At the institutional level, human-carnivore conflicts were reportedly managed through the use of 'destruction permits' issued by parastatal or governmental agencies. Responsibilities varied across provinces e.g., Cape Nature in the Western Cape and the Department of Economic Development and Environmental Affairs in the Eastern Cape. Workshop participants identified a range of carnivore conservation strategies including population monitoring, conservation in protected areas (e.g., national parks and private conservancies), captive breeding and translocations. Government departments tasked with administering legislation to protect carnivores e.g., Biodiversity Act 2004, Threatened or Protected Species Regulations (TOPS), and Convention on International Trade in Endangered Species of Wild Fauna and Flora (CITES), were viewed as being limited by insufficient resources and funding resulting in varied degrees of enforcement across provinces.

\section{Pathways}

Information from participants was synthesised into six discrete transition pathways to activate change in the system (P1 to P6 from top to bottom of the model). P1 is focused on the individual farm or property level and includes adoption of a range of preventive innovations to reduce predation. Four non-lethal producers reported using livestock guarding animals such as dogs and alpacas; the Anatolian and the Africanis Maluti breeds of livestock guarding dogs were reported as the most common breeds. A further four producers preferred aversive deterrents such as flashing lights and sounds especially during vulnerable periods, such as lambing and calving, as well as mixing livestock types (cows with calves and sheep) and kraaling (corralling) at night. However, producers noted the need to frequently change stimuli to reduce carnivore habituation, for example moving the location of the lights or varying the types of sounds. Other practices drew on the principles of holistic resource management to modify grazing styles. For example, livestock were concentrated into a dense herd, primarily to improve herbage growth and soil health, with the co-benefits of reduced livestock predation and parasite infestation. Producers attributed reduced predation to mimicry in denser herds of successful predator avoidance strategies used by wild ungulates. Greater human presence may also deter carnivores due to sounds and scents associated with human activity. More intense livestock management encourages daily inspections of herd health and interventions to reduce livestock vulnerability such as removing sick or injured livestock from the landscape that also provides local employment opportunities and poverty alleviation in rural areas. One non-lethal producer noted that the practice of kraaling livestock at night also decreases the area that needs to be patrolled by guard humans or animals and increases the efficacy of aversive deterrents such as flashing lights.

The second pathway (P2) creates financial incentives, funded by local or international conservation NGOs or government agencies to assist producers to adopt preventive innovations identified in P1. P3 centres on education, capacity building and outreach to build the skills of system actors to utilise preventive innovations such as livestock guardian animals (from P1) that might require training to be effective in the landscape. Producers noted that on-farm demonstrations and field days provided a practical way to learn about P1 tools and practices and exchange ideas. This pathway encompasses knowledge to enhance ecological literacy relating to carnivores within the grazing industry such as their lifecycles, hunting styles, annual patterns of activity, natural prey, and strategies to build producer tolerance towards carnivores. P4 provides a role for conservation specialists, universities and agricultural representatives to collaborate with landholders in decision-making, research and development. These collaborations would test and refine non-lethal tools or practices that work best under the range of production systems, livestock breeds, landscape conditions, and the common carnivores, their associated hunting traits, and sensitivity to the range of available aversive deterrents. 
P5 encourages governance from national to provincial levels to improve policy and appropriately enforce legislation for the protection of large carnivores outside protected areas. The aim of P5 is to better balance the needs of people and wildlife through monitoring and deterrence of illegal poaching. Finally, P6 seeks to harness the power of consumers to make ethical choices in relation to sourcing meat and fibre from producers who adopt preventive innovations. Progress along this pathway could be achieved through branding or labelling that certifies ecosystem-appropriate stewardship and non-lethal approaches to managing predation risk. For example, Fair Game established by the Landmark Foundation provides a premium to producers who refrain from lethal carnivore control and on-sells livestock products to consumers, retailers and restaurants (https://www.landm arkfoundation.org.za/fair-game). At the time of the study, producers considered this market 'niche' in South Africa and felt there would be more demand in European markets. Similarly, workshop participants in particular identified the need to stimulate awareness for predator friendly certified products and demand via targeted media campaigns. The intention of this pathway is to provide a financial incentive to improve ecological stewardship by retaining carnivores in the landscape through demand created by new markets.

\section{Transformed system}

Conservationists and producers described different but complementary aspects of a future transformed system. Livestock producers envisioned an agricultural industry that is adaptive, supports rural communities and livelihoods, and contributes to local and global food security. Livestock are protected from harm associated with stress, injury or death through reduced exposure to predation risks. This is underpinned by an enabling environment in which support networks provide incentives and build capacity for producers to learn about and adopt contextually appropriate preventive non-lethal innovations and holistic regenerative agricultural practices. A fundamental component of such support networks is the provision of financial support for landholders to offset the costs of adopting practices such herders, guardian animals and regenerative agriculture. The expansion of sustainability certification to include a predator-friendly marketing scheme would allow participating producers to reach new market segments in South Africa and internationally and reward producers who are ecologically focused.

Conservationists envisioned a desirable future grazing system in which populations of carnivores are stable and viable. Ecosystems are "resilient" and "healthy" and provide "valuable ecosystem services". Secure long-term funding enables the creation of governance structures for greater enforcement of regulations, and policies that effectively deter carnivore persecution as well as long-term monitoring of carnivore populations to aid decision making. These arrangements are underpinned by well-managed, resourced, and transparent government institutions that support conflict avoidance research and development, and coexistence. Furthermore, local communities and actors in conservation initiatives are essential for wildlife conservation and therefore fundamental to the transformed system. Local communities can be challenged by living alongside carnivores but can also share in the benefits of incomes derived from sustainable, low impact wildlife eco-tourism. The combination of the pathways would likely mainstream the adoption of predator-friendly farming practices and increase the health and resilience of livestock, land and livelihoods. Overall, the model illustrates how coexistence can be achieved in rangeland landscapes in South Africa.

\section{The United States of America model}

A similar change model was developed for rangeland grazing systems of the western USA (Fig. 3).

\section{System drivers}

Participating conservationists and producers (ranchers) identified the recovery of large carnivores as one of the most obvious changes occurring in extensive grazing systems in western USA. While species recovery may be counted as a success, other key stakeholders, particularly producers and some government representatives, viewed this as a driver of conflict. Interviewees suggested that increasing urbanization is driving change in the perception of wildlife in communities with greater value placed on the opportunity to see large carnivores in the wild. At the same time demand is growing for food and fiber products that are ethical, healthy, environmentally sustainable, and incorporates practices that promote good animal welfare and environmental stewardship. This shift also contributes to an urban-rural divide over carnivore management with urban communities opposing lethal management that is more widely supported by rural communities.

\section{Current system}

Business-as-usual in western grazing was viewed by participants as undergoing change. As populations of large carnivores begin to recover (i.e., no longer classified as endangered) their management is transferred from the Federal jurisdiction, under the U.S. Fish and Wildlife Service, to state agencies. State policies and the species' population status were perceived as factors influencing the perception and treatment of carnivores. For example, the Idaho Department of Fish and Game awarded The Foundation for Wildlife Management grants of $\$ 20,000$ in 2018 and $\$ 13,220$ 


\section{SYSTEM DRIVERS}

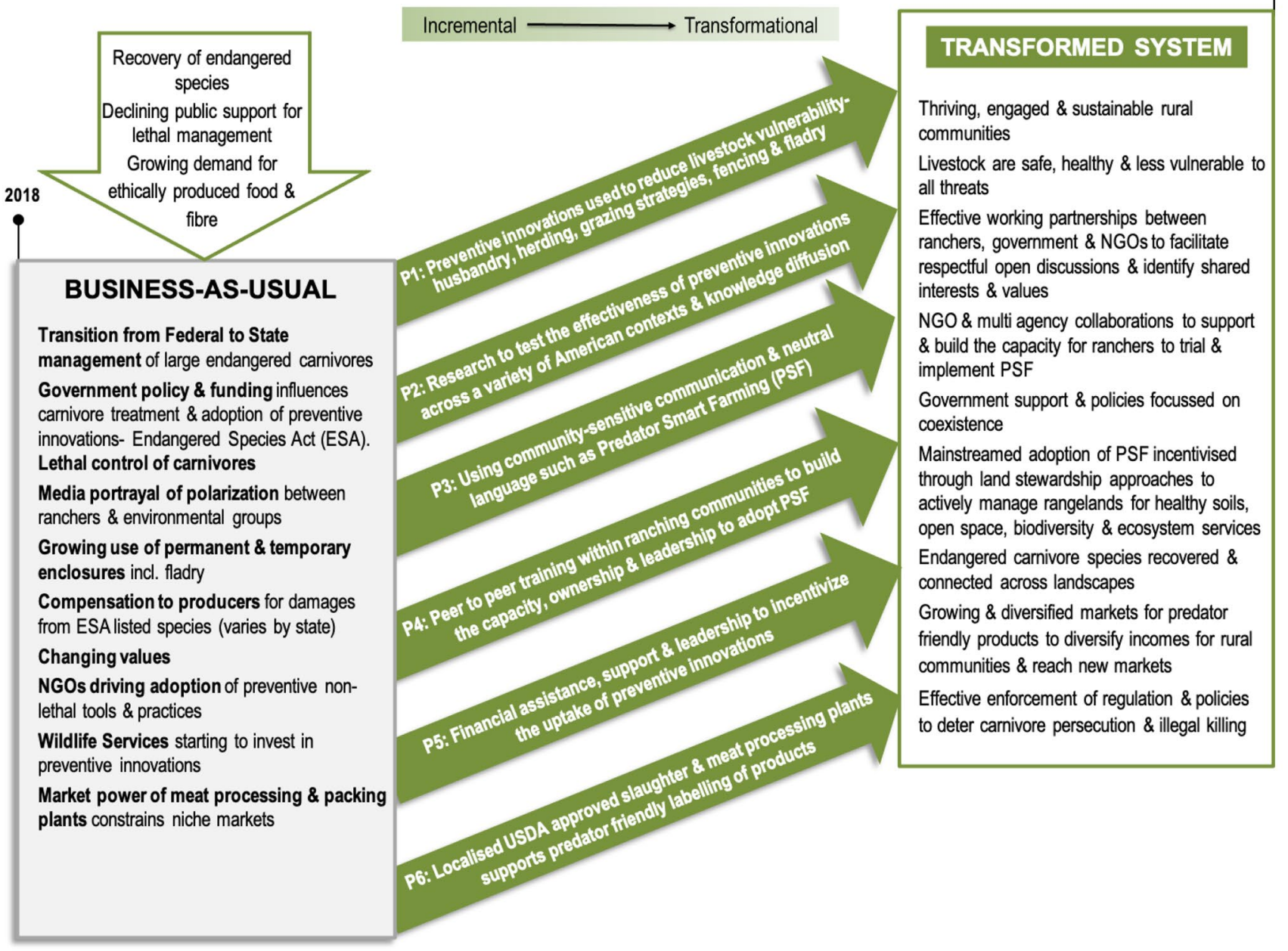

Fig. 3 A model of transformative change in extensive grazing systems in western United States of America. Pathways are numbered P1 to P6

in 2020 to reimburse hunters and trappers for expenses incurred while killing wolves. These grants effectively provide a bounty to kill wolves in Idaho (IDFG 2018, 2020). Environmental and wildlife protection NGOs argued that the liberal use of lethal control results in environmental, social and animal welfare harms. However, hunting groups argue that carnivores reduce populations of valued game species such as deer and elk. A combination of these factors has caused social conflicts between seemingly opposing groups such as ranchers and environmental advocates.

Interviewees from conservation NGOs spoke of changing community values in terms of growing public awareness and appreciation of the value of wildlife, such as wildlife viewing, supporting environmental protection, and declining support for lethal carnivore management and trophy hunting. However, two policy makers noted that support for hunting remains strong in rural communities. The shift towards non-lethal management has been facilitated by conservation groups pressuring government agencies to change the laws and funding allocations for wildlife management. For example, Wildlife Services is investing in preventive non-lethal innovations with $\$ 1.38 \mathrm{M}$ of US Federal funding allocated for wildlife conflict-prevention specialists across ten states (https://tinyurl.com/y42hzsjo). This initiative is supported by increasing evidence of the efficacy of preventive innovations over lethal control at the local scale. As consumers' awareness rises in relation to lethal control of wildlife for livestock protection so too does support for Predator Friendly certified products. However, producers noted the challenges in participating in these kinds of labelling programs due to market power of meat processing and packing plants, with producers lacking control over how products are labeled once they sell into that system, and their ability to ensure supply to these markets. 


\section{Pathways}

As with the South African model, information from participants was synthesized into six discrete transition pathways to realize a transformation in rangelands grazing. P1 centres on the adoption within ranching communities of preventive innovations (both tools and practices) to reduce the vulnerability of livestock to predation and carnivores to persecution (Fig. 3). Interviewees identified a range of actions including:

- Guarding livestock (herders, range riders and guardian animals),

- Husbandry practices that reduce encounter rates between predators and livestock (e.g., range riding, tighter herding of livestock especially at night using night pens, reducing isolation of young calves and lambs from their mothers, and avoidance of heavily forested areas, riparian areas or sites of known carnivore activity),

- Optimising herd health (e.g., sound vaccination, handling and nutrition protocols),

- Removing attractants such as livestock carcasses and bone yards,

- Planned grazing strategies (e.g., more intensive yet short term grazing, use of permanent and temporary enclosures or installation of additional watering points).

P2 focusses on research to test the effectiveness of preventive non-lethal innovations in a range of production contexts and variety of carnivorous species. This research provides insights into carnivore behavior, the underlying factors driving conflicts, the location of conflict hotspots and refinement of the protocols for the use of existing preventive innovations (e.g., deployment of fladry or use of livestock guardian animals) considered to be the most effective practices by non-lethal ranchers and environmental NGOs.

P3 recognizes that clear and effective communication is essential to achieving long-term successful carnivore conservation in multi-use landscapes. The concept of Predator Smart Farming (PSF) emerged from the stakeholder interviews as the producers' preferred term. PSF was not only more palatable for ranchers than the terms 'wildlife-' or 'predator-friendly' but also had greater alignment with ranching communities' values. The word 'smart' appealed to producers who were keen to use innovative tools and practices to 'outsmart' carnivores. PSF was described as a holistic and conscientious approach to agriculture to increase the resilience of landscapes, animals (domesticated and wild) and rural livelihoods, encompassing three key aspects. Firstly, it focuses on reducing the vulnerability of livestock to risks, including disease, environment (e.g., poisonous plants), climate (e.g., drought) and predation. Secondly, it has a social-ecological stewardship mindset, identified as common among practitioners of 'regenerative agriculture' (Gibbons 2020), that fosters ethical and responsible interactions within production landscapes to maintain the underlying ecosystem and landscape processes. Thirdly, PSF fosters financially resilient livelihoods that reduce the costs and capitalise on the benefits of large carnivores in the landscape (e.g. reduced grazing pressure and/or spread of disease e.g. brucellosis from wild herbivores). The expanded framing of grazing practice, shifts the emphasis from carnivore control to land and livestock management, would create the space to initiate and hold more productive conversations about large carnivore conservation.

The adoption of PSF is reinforced by $\mathrm{P} 4$ that recognises that peer to peer education (i.e., producer to producer), knowledge exchange and training within ranching communities is an effective way to overcome the socio-cultural resistance towards new tools and practices. P4 builds capacity (skills, knowledge and confidence) and ownership of PSF at the grassroots level supported by an enabling environment that fosters effective working partnerships between ranchers, government and NGOs. Examples include the Tom Miner Basin Association (http://tomminerbasinassociation. org/) and the Blackfoot Challenge (https://blackfootchalle nge.org/). Capacity building efforts would be assisted by P5 that works to, firstly, develop policy that encourages the use of preventive innovations as a first response to managing conflict. Secondly, P5 acts to expand the array of tools that can be utilized to reduce predation risk and reduce reliance on lethal control. For example, in eastern Oregon a rancher must show they are suffering ongoing loss from predation after implementing two preventive innovations such as fladry (suspended strips of fabric or coloured flags that move in a breeze) or aversive deterrents before a lethal control order can be issued (Oregon Department of Fish and Wildlife 2014). Thirdly, P5 includes financial incentives for adoption of preventive innovations, such as NGO programs that make a co-contribution to non-lethal deterrents in regions where large carnivores are still federally listed species, in addition to government grants to overcome the initial financial barrier to adoption. Such support to producers was perceived by conservation NGOs as a way to create an enabling environment, initiate conversations and start building trust with farming communities that may hold negative attitudes to carnivores, conservation organisations and government.

The final pathway, P6, focuses on increasing the number of local United States Department of Agriculture (USDA) approved slaughter and meat processing plants to support producers who want to run their own labelling schemes. P6 encourages growth in the market for PSF products, allows producers to reach new consumers and rewards producers who have a more holistic mindset. However, NGOs and some producers agreed that P6 requires increased demand for certified products. Creating markets for PSF products requires increased consumer education about 
the ecological, animal welfare and socio-economic benefits of PSF products. Environmental NGO participants in the USA indicated that expanded PSF labelling schemes could counter-balance the high market power of feedlots and huge slaughtering houses in the Midwestern USA and would enable environmentally conscious labelling schemes to move from niche to more mainstream. More importantly product labelling is needed to recognize the efforts (learning, costs etc.) of transitioning from 'conventional' to alternative livestock production systems for long-term sustainability.

\section{Transformed system}

The vision of a desirable future includes rural communities that are thriving, engaged and ecologically sustainable supported by a diversified rural economy. Livestock are safe, healthy and less vulnerable to all threats encountered in extensive grazing, supported by an enabling environment that fosters effective working partnerships between ranchers, government and NGOs. Partnerships are based on respectful open discussions and collaboration that identifies shared interests and goals such as healthy ecosystems, agricultural viability and food security. This vision serves common interests, not special interests or entrenched positions. Ranchers, NGOs and agencies collaborate to build the capacity to research, trial and implement preventive innovations that are suited to local landscapes, economies and livestock operations. This collaboration is facilitated by government support, policies and regulations that fund research, promote dissemination of knowledge about large carnivores, effectively deter illegal killing and encourage human-carnivore coexistence.

Carnivore management forms part of the larger regenerative agriculture movement, which prioritises and incentivises approaches that actively manage rangelands for healthy soils, open space and greater biodiversity and ecosystem services. Our models incorporate transformed systems where once endangered large carnivores inhabit their historical range and contribute to ecosystem health and functioning supported by a sufficient natural prey base. Tolerance towards large carnivores is enhanced by the mainstreamed adoption of preventive innovations. NGOs and government help to over-come financial and capacity barriers such as the material costs, knowledge gaps, and necessary labour to implement PSF practices. Markets for a diverse range of predator-friendly agricultural products are growing and help sustain rural communities and incentivise a holistic eco-centric approach to land management.

\section{Discussion}

Through engagement with a range of key stakeholders, we developed two qualitative models of change that show transition from business-as-usual via various pathways to transform interactions between humans and large carnivores from conflict to coexistence in rangeland systems (Figs. 2 and 3). The engagement drew upon various sources of knowledge, highlights a range of views on human-carnivore coexistence and identifies multiple, mutually supporting pathways towards a transformed future. The current system, described in terms of system drivers and business-as-usual, in each country has evolved under local historical, political, socio-cultural, economic and biophysical contexts. Despite these variations in local context, there are many similarities in these rangeland grazing systems. In both South Africa and the USA, there is a reliance on lethal methods such as shooting and trapping to resolve human-carnivore conflicts (McManus et al. 2015; Treves et al. 2016). In both countries, carnivore persecution was justified by the desire to protect agricultural productivity and livelihoods. However, the differences between the countries primarily relates to the institutional context and level of support for producers for lethal carnivore control. For example, it appears that in the last four decades producers in the United States were provided with significantly more institutional support for lethal control than in South Africa. This institutional support heavily subsidised the cost of predator control for US producers. In contrast, agricultural policy in South Africa during the 1980s saw a withdrawal from subsidised lethal carnivore control including bounty payments, support for hunting with dogs and the provision of poisons (Nattrass et al. 2020). These subsidies were replaced with predator hunting services by private consultants or undertaken by producers themselves. A recent South African study (Brink et al. 2021) found that the use of poisons for lethal carnivore control is widespread. An estimated $31 \%$ of the farmers surveyed over 5 -year period used poisons against carnivores because it was considered one of the least labour-intensive lethal control options (Brink et al. 2021). Although developed independently, as each change model deals with human-carnivore interactions in extensive grazing systems, it is unsurprising that there are similarities in pathways from each country.

At the heart of each model are the potential pathways that represent incremental changes (e.g., use of predator deterrents on an individual farm) that culminate in longerterm transformative change (i.e., coexistence). The initial actions from business-as-usual onto the transition pathways can be considered as critical low-risk steps that avoid the disruption to the system that might occur if ecological 
thresholds were de-stabilized (Price and Hacker 2009). The key areas of overlap in the pathways include the various leverage or intervention points to encourage adoption of preventive innovations via incentives, capacity building and governance structures that balance human and carnivore needs. This aligns with the work of Chan et al. (2020) who identified levers and leverage points that are key to achieving transformations towards greater global sustainability. These levers include pre-emptive action (P1\&4 in South African model and P1\&2 in USA model), incentives and capacity building (P2,3\&4 in South African model and P4\&5 in USA model), coordination across different sectors and jurisdictions (P3\&4 in South African model and $\mathrm{P} 2,3 \& 4$ in USA model), adaptive decision-making and environmental law and its enforcement (P5 in South African model) (Chan et al. 2020). While progress along all pathways is important to achieve transformation, they operate at varying scales (from national to regional and local), and mutually reinforce each other to create 'sticky' change that over time becomes more acceptable and durable ensuring a lower likelihood of being reversed by a change in policy (Levin et al. 2012) or dis-adopted (Chinseu et al. 2019).

Governance is critical to any intentional effort to shape transformations towards sustainability (Patterson et al. 2015). Governance arrangements that encourage effective partnerships between producers, government and NGOs are vital to facilitate respectful open discussions that use neutral language and identify shared interests and values (Madden and McQuinn 2014; Chan et al. 2020). Therefore, new institutional arrangements that promote ecosystem governance in ways that are adaptable, flexible, and incorporate multiple stakeholder values are required to facilitate transitions away from business-as-usual (Walker and Salt 2006; Head and Alford 2015). For example, in USA, the Oregon Wolf Plan "emphasizes the importance and mandates the implementation of non-lethal efforts to reduce wolf-livestock conflict before lethal removal is considered in all phases of wolf management" (Oregon Department of Fish and Wildlife 2014, p. 10). These kinds of policies challenge the current regime (business-as-usual) and have the power to leverage transformation because they shift the system from its dominant mode of operation i.e., reliance on lethal carnivore control toward a future system that incorporates multiple values (production and wildlife conservation and welfare) and human-carnivore coexistence. This is an important consideration when planning for coexistence as it requires decision making that accounts for the interests of a variety of stakeholders (Marchini et al. 2019).

Another factor that is adding pressure to the current regime particularly in the USA relates to the shift in consciousness about the ethics of killing large numbers of wildlife to protect special interests (i.e. livestock production).
Research from the USA indicates that as the public has become increasingly urban and modernised, values have shifted away from domination over nature towards mutualism with nature (Manfredo et al. 2009), with the public increasingly attributing intrinsic value to wildlife. Furthermore, developments in both conservation and animal welfare sciences have demonstrated the importance of large carnivores in maintenance of the health and function of ecosystems (Ripple et al. 2014) and the negative welfare implications of the methods commonly used in lethal control (Littin and Mellor 2005). Within urban communities there has been a decline in public support for lethal methods and a shift in favor of finding solutions that can protect agriculture and carnivores simultaneously (Graham et al. 2005; Slagle et al. 2013; Manfredo et al. 2018). This has created a greater impetus for conservation NGOs as agitators of change to pressure livestock industries to transition away from traditional lethal approaches towards the adoption preventive innovations that support wildlife persistence (Young et al. 2019).

When producers feel their livelihoods and way of life are under threat, this can contribute to polarisation between groups who hold different values and social norms. Therefore during 'high stakes' conversations such as discussions about carnivore management, the use of neutral language is essential to building openness, trust and collaboration to explore shared goals. It is important to focus on mutual benefits and use language that de-escalates polarized schisms among stakeholders involved in rangeland management. A key finding from the USA model is the concept of PSF because it shifts the focus from carnivores towards three aspects: (1) livestock management and husbandry to reduce predation risk and carnivore persecution, (2) social-ecological stewardship to build the resilience and productive capacity of landscapes, and (3) security of rural livelihoods, all of which are of paramount importance to farming communities. The social-ecological stewardship mindset of PSF focusses on restoring resilient production landscapes that are capable of producing a full suite of ecosystem services including soil carbon sequestration, water retention and biodiversity (Gosnell et al. 2019; Schurch et al. 2021). Whereas, investigating ways to secure livelihoods focusses on reducing the costs and capitalising on the benefits of large carnivores in the landscape such as reduced grazing pressure from wild herbivores or diversifying incomes through eco-tourism and farm stays (Prowse et al. 2015). This expanded framing of grazing we believe would assist in initiating conversations about large carnivore conservation and builds positive working relationships between wildlife managers, government agencies, environmental and animal protection NGOs, livestock producers and local communities.

In both models pathways focus on the adoption of contextually appropriate preventive innovations by producers. 
These include deterrents, temporary or permanent enclosures, guardian animals and husbandry protocols, because they are central to reducing livestock vulnerability and predation risk (Baker et al. 2008; van Eeden et al. 2018a, b). The benefits of deterrents and enclosures have been discussed extensively (Shivik et al. 2003; Stone et al. 2017; Young et al. 2019). Yet husbandry in general remains an under-utilized practice for the management of predation. Three non-lethal producers from the USA suggested that many preventive innovations are forms of active livestock management and the focus should switch from controlling carnivores to the core concern of maintaining livestock health and resilience. Active management includes human presence to observe for signs of disease, nutritional deficiencies or restlessness, and extra vigilance during high risk periods (i.e. lambing and calving) or when carnivores are most active (White 2012; Stone et al. 2017). Woodroffe and Frank (2005) reported similar findings about the value of livestock husbandry practices to reduce predation risk in rangelands in northern Kenya, Africa. In addition, Ogada et al. (2003) identified that predation rates were reduced when livestock were herded by day and enclosed in traditional corrals (bomas) at night, guarded by humans and dogs. In our study, participants from wildlife agencies and NGOs saw a key role here in assisting producers in adoption of active management through increasing their understanding of patterns in carnivore behaviour, that is, how and when carnivores move through certain parts of the landscapes, seasons when they are most active and how hunting behaviour influences livestock vulnerability (Baker et al. 2008). This knowledge informs risk reduction strategies, such as planned grazing to avoid areas that result in an ambush attack by a carnivore and/or concentrating livestock into a dense herd as a predator avoidance strategy (Bøving and Post 1997; Graham et al. 2005; Fryxell et al. 2007). Producers, particularly in South Africa, believed higher density herds offer various benefits by utilising a smaller part of the property for grazing, thus allowing longer rest periods to encourage plant growth and soil health (McManus et al. 2018). This grazing style requires increased human presence from a herder or 'range rider' to move livestock while also providing realtime monitoring of livestock and investigating more closely the causes of the livestock losses (as these are often attributed incorrectly to predator activity) (Brown 2011; Stone et al. 2017). However, producers should not be expected to develop alone the necessary depth of 'ecological literacy' required for successful active management. Wildlife agencies and NGOs must collaborate closely to engage producers in dialogue that could foster a greater understanding of stakeholders interests and goals.

In each model the pathways focus on institutional support to facilitate adoption of preventive innovations ( $\mathrm{P} 2, \mathrm{P} 3$ in the South African model and P2, P4 and P5 in the USA model).
Support is often needed to overcome the barriers to adoption of preventive innovations and include financial and policy incentives and capacity building, which are vital for change creation (Chan et al. 2020). For example, in both countries financial support or cost sharing of investment with producers by NGOs, government agencies or industry bodies is evident, i.e. the Landmark Foundation in South Africa and the Wood River Wolf Project in Idaho, USA. NGOs purchased deterrents including livestock protection collars and aversive technology (lights and horns) that were loaned to producers, along with training on their deployment (McManus et al. 2015; Stone et al. 2017). These initiatives encouraged greater adoption by sceptical producers over the longer-term. Similarly, Rust and Marker (2013) reported that subsidising the cost of livestock guarding dogs, kraal building materials and herder wages would be more effective than compensation in promoting practice adoption in Namibia. However, financial incentives alone may be insufficient to stimulate adoption of preventive innovations and wildlife tolerance (Naughton-Treves et al. 2003; Dickman et al. 2011).

While NGOs and government agencies have a role to play in providing institutional support, a more powerful tool to facilitate adoption is social learning via peer-to-peer support and training from within agricultural communities (Rodela 2011). Each model contains pathways focused on activities that build producer capacity (knowledge, skills and competencies) to choose and adopt preventive innovations suited to their particular context. Farmers in general are viewed as innovators, continuously adapting technology and practices to changing environmental conditions and socio-economic circumstances (Pannell et al. 2006). However, individuals vary in their degree of pro- and re-activeness in the adoption of new tools and practices, which can affect the wider achievement of sustainability goals. Pannell and Vanclay (2011) identified many conservation practices as preventive innovations and discussed two key factors that increase the likelihood of adoption i.e., high relative advantage (i.e. the new practice is superior to the current practice); and, trialability (the practice or innovation can be tested and learned about prior to adoption) (Pannell et al. 2006; Pannell and Vanclay 2011). Trialability is affected by technical attributes of the practice such as cost of on-farm experimentation, the scale of adoption required, the observability of the results and the complexity of the innovation (Pannell et al. 2006; Pannell and Vanclay 2011). Social networks provide valuable sources of knowledge and experiences that farmers draw upon for reference (Leys and Vanclay 2011). This is because individuals are generally more receptive to information from people they consider to be within their own reference group (i.e. people of similar livelihood, gender, economic status, geography, beliefs or values) (Stern 2018). van Eeden (2020) found that a social identity, such as farmer or animal rights advocate, is a strong predictor of attitudes toward wildlife 
management. Peer-to-peer training also fosters strong social connections and encourages collective action through the creation of social norms (Amel et al. 2017). Knapp and Fernandez-Gimenez (2009) found that informal social networks and formal peer learning networks are used by ranchers in Colorado to acquire new knowledge. Demonstration of successful adoption of preventive innovations by producers generally encourages adoption by other local producers as they have seen how it works in their local context, thereby, lowering their risks (time, cost, failure) of adoption and increasing the perceived credibility of the practice facilitating adoption clusters (Pannell et al. 2006; Pannell and Vanclay 2011).

There is a clear need for ongoing research into the effectiveness of the range of preventive innovations in various contexts to fill current knowledge gaps (Stone et al. 2017). Pathways that address the need for such research appear in both the USA and South African models and are supported by findings suggesting that the willingness of producers to adopt such innovations often relies on proof of their efficacy (Young et al. 2019). However, many innovations may not suit all grazing systems, may be impractical to deploy in some situations or may not offer universal protection from all carnivores (Baker et al. 2008). Engaging farmers in research to identify and fill these research gaps is therefore important. Furthermore, there is an array of complex variables affecting predation rates including terrain, vegetation, alternative prey availability and season, as well as biology and behavior of the carnivore species of concern, such as territoriality and cognition, which influence the success of preventive innovations in specific situations (Baker et al. 2008). For example, a number of studies have proven the general effectiveness of livestock guardian dogs (LGDs) (van Bommel and Johnson 2012; van Eeden et al. 2018a, b; Spencer et al. 2020). However, in the USA when wolves have young pups in a den between April to June they may attack and kill LGDs to defend their pups, so alternative preventive innovations should be used during this period (Stone et al. 2017). Involving producers in research and decision-making may imbue a sense of ownership over the solutions as well as embed stewardship values. In Wilson et al. (2005) ranchers were engaged to provide geographical information on human activities in the landscape that may attract bears such as calving areas and beehives. This information was then used to build a geo-spatial picture of potential conflict hotspots and inform predation reduction strategies. Furthermore, Colloff et al. (2017) found that knowledge co-production between researchers, practitioners, and citizens "supports collective action and reflection directed towards improving the management of human and environmental interrelations" (Colloff et al. 2017, p. 1013). This is echoed by Ives et al. (2020) who assert that "effective action for sustainability is increasingly understood to require not only systems knowledge (technical knowledge of how systems function) but also normative knowledge (how systems ought to be), and transformative knowledge (how to change systems to more desirable states)" (Ives et al. 2020, p. 212). As this paper has shown engaging various stakeholders is critical as there is more than one way of defining the challenge of human-carnivore coexistence, and a need to include various sources of knowledge to identify pathways towards a transformed future.

Increasingly consumers have a role in supporting producers that adopt predator friendly practices. P6 in both models focusses on predator friendly certification and labelling to foster coexistence between humans and carnivores in livestock grazing enterprises. NGOs such as the Wildlife Friendly Enterprise Network with the Predator Friendly label (http://www.predatorfriendly.org) and the Landmark Foundation in South Africa which operates under the label Fair Game support producers that refrain from lethal carnivore control, diversify markets and satisfy a growing demand. During each interview producers were asked about their willingness to participate in such a program. Overall non-lethal producers in both countries did not consider the economic benefits alone to be a sufficient reason to adopt predator friendly tools and practices. Yet when considered holistically alongside the benefits for livestock and landscape health, producers agreed that this type of labelling scheme could provide recognition of important ecological stewardship efforts. This finding aligns with research about Predator-Friendly Beef Certification which found that ranchers in Washington, USA that were in favor of predator-friendly beef labeling were compelled by the consumer education and outreach opportunities rather than a new source of income (Bogezi et al. 2019). In our study lethal producers were not in favor of such a labelling scheme as they felt that predation costs might outweigh the premium received and did not want to be seen by neighbors and peers as being 'friendly' towards predators, a finding also reported in Bogezi et al. (2019). However, all producers rely on consumer demand for their products and favored exploration of ways to diversify their markets.

The vision of a preferred future synthesised in each of the models was remarkably similar and focused on three key areas: carnivore conservation to maintain ecosystem resilience, sustainable rural communities and the empowerment of stakeholders in the governance of natural resources. In both models, conservation goals included the recovery of the populations of carnivores and safeguarding carnivores from human persecution. Stakeholders articulated that mitigating human wildlife conflict and fostering coexistence would require new management practices such as PSF to become mainstream in extensive grazing systems. Policies that support preventive innovations and research combined with effective enforcement of regulation coupled with policies to deter carnivore persecution and illegal killing were central to 
achievement of a transformed system. Producers envisioned an agricultural system that supports and sustains rural communities and livelihoods and healthy productive landscapes in which livestock are safe and less vulnerable to all threats.

\section{Conclusions}

In the context of global sustainability, the notion of transformation is increasingly used to characterise aspirations to transition from current unsustainable and inequitable mechanisms toward a more sustainable, inclusive, and equitable future (Patterson et al. 2017; O'Brien 2018). We present two transformative change models that examine human-carnivore coexistence in extensive rangeland grazing systems in South Africa and the United States. The models were developed through extensive engagement with 85 stakeholders (livestock producers, landholders, government and representatives of conservation NGOs) using an integrative sustainability framework (Sellberg et al. 2017). Pathways to coexistence that encompass a range of stakeholder perspectives are a major contribution towards human dimensions of conservation. Without bold action to transform our current systems, we risk losing one million species within decades (Ripple et al. 2017; Ferrier et al. 2019). Consequently this paper articulates the essential pathways to intervene in the current social-ecological system to facilitate outcomes that are more equitable and just for multiple species. An important finding is a new concept of Predator Smart Farming, a holistic and conscientious approach to agriculture to increase the resilience of landscapes, animals (domesticated and wild) and rural livelihoods. The two models developed here show the pathways towards incremental, equitable and just transition from the current system towards a future system that realizes multiple desirable outcomes including diverse and thriving rural livelihoods, biodiversity conservation and maintenance of ecosystem services, and more peaceful, just, and compassionate relationships with animals.

Acknowledgements We wish to acknowledge the individuals who reviewed the models featured in this publication. This research was generously supported by the Research Excellence Scholarship provided by the University of Technology Sydney. The South African research was facilitated by the Landmark Foundation who acknowledge support from the National Department of Environment, Forestry and Fisheries, Development Bank of Southern Africa, Global Environmental Facility, Green Fund, United Nations Environmental Program, United Nations Development Program, and Landmark Foundation Trust.

Author contributions LB conducted the data collection (workshop and interviews), analysed the data and drafted the majority of the manuscript. Dr J conducted the data collection (workshop and South African interviews), assisted with analysis and interpretation of results, contributed to the discussion and reviewed the manuscript. Dr. W assisted with identifying and recruiting stakeholders to interview, helped to refine thinking and interpretation of results. Dr. MM reviewed the manuscript and contributed to refining the South African model and clarified the South African context. SS identified and assisted with recruiting American stakeholders to interview, reviewed and contributed to the United States model and clarified the US context. SS identified and recruited American stakeholders to interview, reviewed and contributed to the United States model and clarified the USA context. Dr. S identified and recruiting South Africa stakeholders to interview, reviewed and contributed to the South African model and clarified the country context. HZ contributed ideas about human-carnivore coexistence, the need for financial resiliency on ranches to foster coexistence and refined thinking in the manuscript.

Funding The research has been supported by the Research Excellence Scholarship provided by the University of Technology Sydney.

Data availability The interview questions are available to review upon request and/or can be provided as supplementary material.

Code availability MAXQDA software (VERBI GmbH version 18.2.0).

\section{Declarations}

Conflict of interest The authors declare that they have no conflict of interest.

Ethical approval ETH18-2568-HREC University of Technology Sydney.

Consent to participate All of the stakeholders engaged in the research provided informed consent to participate in the research.

Consent for publication I declare that this is original work and has not been published before, nor is it under consideration for publication anywhere else. This publication has been approved by all co-authors as well as by the responsible authorities.

\section{References}

Abson, D.J., J. Fischer, J. Leventon, J. Newig, T. Schomerus, U. Vilsmaier, H. von Wehrden, P. Abernethy, et al. 2017. Leverage points for sustainability transformation. AMBIO. https://doi.org/ 10.1007/s13280-016-0800-y.

Amel, E., C. Manning, B. Scott, and S. Koger. 2017. Beyond the roots of human inaction: Fostering collective effort toward ecosystem conservation. Science. https://doi.org/10.1126/science.aal1931.

Baker, P.J., L. Boitani, S. Harris, G. Saunders, and P.C.L. White. 2008. Terrestrial carnivores and human food production: Impact and management. Mammal Review 38: 123-166. https://doi.org/10. 1111/j.1365-2907.2008.00122.x.

Berger, K.M. 2006. Carnivore-livestock conflicts: Effects of subsidized predator control and economic correlates on the sheep industry. Conservation Biology 20: 751-761. https://doi.org/10.1111/j. 1523-1739.2006.00336.x.

Bergstrom, B.J. 2017. Carnivore conservation: Shifting the paradigm from control to coexistence. Journal of Mammalogy 98: 1-6. https://doi.org/10.1093/jmammal/gyw185.

Bergstrom, B.J., L.C. Arias, A.D. Davidson, A.W. Ferguson, L.A. Randa, and S.R. Sheffield. 2014. License to kill: Reforming federal wildlife control to restore biodiversity and ecosystem function. Conservation Letters 7: 131-142. https://doi.org/10.1111/ conl.12045. 
Beschta, R.L., and W.J. Ripple. 2009. Large predators and trophic cascades in terrestrial ecosystems of the western United States. Biological Conservation. https://doi.org/10.1016/j.biocon.2009. 06.015.

Bogezi, C., L.M. van Eeden, L. Wirsing, and J. Marzluff. 2019. Predator-friendly beef certification as an economic strategy to promote coexistence between ranchers and wolves. Frontiers in Ecology and Evolution 7: 1-15. https://doi.org/10.3389/fevo.2019.00476.

Boronyak, L., B. Jacobs, and A. Wallach. 2020. Transitioning towards human-Large carnivore coexistence in extensive grazing systems. AMBIO. https://doi.org/10.1007/s13280-020-01340-w.

Bøving, P.S., and E. Post. 1997. Vigilance and foraging behaviour of female caribou in relation to predation risk. Rangifer 17: 55. https://doi.org/10.7557/2.17.2.1302.

Brink, C.W., R.L. Thomson, A. Amar, M. Girardello, and A. Santangeli. 2021. Prevalence and drivers of poison use by South African commercial farmers and perceptions of alternative livestock protection measures. Ambio. https://doi.org/10.1007/ s13280-020-01461-2.

Brown, P. D. 2011. Wolves and Livestock: A review of tools to deter livestock predation and a case study of a proactive wolf conflict mitigation program developed in the Blackfoot Valley, Montana. Montana The Magazine Of Western History. https://scholarwor ks.umt.edu/etd/1193

Bruskotter, J.T., and D.C. Fulton. 2012. Will hunters steward wolves? A comment on Treves and Martin. Society and Natural Resources 25: 97-102. https://doi.org/10.1080/08941920.2011.622735.

Bryant, A., and K. Charmaz. 2010. The evolving nature of grounded theory method: The case of the information systems discipline. The SAGE Handbook of Grounded Theory. https://doi.org/10. 4135/9781848607941.n16.

Cardinale, B.J., J.E. Duffy, A. Gonzalez, D.U. Hooper, C. Perrings, P. Venail, A. Narwani, G.M. MacE, et al. 2012. Biodiversity loss and its impact on humanity. Nature 486: 59-67. https://doi.org/ 10.1038/nature11148.

Chan, K.M.A., D.R. Boyd, R.K. Gould, J. Jetzkowitz, J. Liu, B. Muraca, R. Naidoo, P. Olmsted, et al. 2020. Levers and leverage points for pathways to sustainability. People and Nature. https:// doi.org/10.1002/pan3.10124.

Chinseu, E.L., L.C. Stringer, and A.J. Dougill. 2019. An empirically derived conceptual framework to assess dis-adoption of conservation agriculture: Multiple drivers and institutional deficiencies. Journal of Sustainable Development. https://doi.org/10.5539/jsd. v12n5p48.

Cockburn, J., G. Cundill, S. Shackleton, and M. Rouget. 2018. Towards place-based research to support social-ecological stewardship. Sustainability (Switzerland). https://doi.org/10.3390/su100 51434.

Colloff, M.J., S. Lavorel, L.E. van Kerkhoff, C.A. Wyborn, I. Fazey, R. Gorddard, G.M. Mace, W.B. Foden, et al. 2017. Transforming conservation science and practice for a postnormal world. Conservation Biology. https://doi.org/10.1111/cobi.12912.

Curry, A., and A. Hodgson. 2008. Seeing in multiple horizons: Connecting futures to strategy. Journal of Futures Studies. https:// www.researchgate.net/publication/253444667.

Dickman, A.J., E.A. Macdonald, and D.W. Macdonald. 2011. A review of financial instruments to pay for predator conservation and encourage human-carnivore coexistence. Proceedings of the National Academy of Sciences. https://doi.org/10.1073/ pnas.1012972108.

Djenontin, I.N.S., and A.M. Meadow. 2018. The art of co-production of knowledge in environmental sciences and management: Lessons from international practice. Environmental Management 61: 885-903. https://doi.org/10.1007/s00267-018-1028-3.

Estes, J.A., J. Terborgh, J.S. Brashares, M.E. Power, J. Berger, W.J. Bond, S.R. Carpenter, T.E. Essington, et al. 2011. Trophic downgrading of planet earth. Science. https://doi.org/10.1126/ science. 1205106.

Ferrier, S., K.N. Ninan, P. Leadley, R. Alkemade, L.A. Acosta, H.R. Akçakaya, L. Brotons, W. Cheung, et al. 2019. Summary for policymakers of the methodological assessment of scenarios and models of biodiversity and ecosystem services of the Intergovernmental Science-Policy Platform on Biodiversity and Ecosystem Services. Secretariat of the Intergovernmental Science-Policy Platform on Biodiversity and Ecosystem Services. https://doi.org/10.1590/1676-0611201600010001.

Fischer, J., D.B. Lindenmayer, and A.D. Manning. 2006. Biodiversity, ecosystem function, and resilience: Ten guiding principles for commodity production landscapes. Frontiers in Ecology and the Environment 4: 80-86. https://doi.org/10.1890/15409295(2006)004[0080:BEFART]2.0.CO;2.

Fischer, J., B. Brosi, G.C. Daily, P.R. Ehrlich, R. Goldman, J. Goldstein, D.B. Lindenmayer, A.D. Manning, et al. 2008. Should agricultural policies encourage land sparing or wildlifefriendly farming? Frontiers in Ecology and the Environment 6: 380-385. https://doi.org/10.1890/070019.

Folke, C., T. Hahn, P. Olsson, and J. Norberg. 2005. Adaptive governance of social-ecological systems. Annual Review of Environment and Resources 30: 441-473. https://doi.org/10.1146/ annurev.energy.30.050504.144511.

Fryxell, J.M., A. Mosser, A.R.E. Sinclair, and C. Packer. 2007. Group formation stabilizes predator-prey dynamics. Nature 449: 1041-1043. https://doi.org/10.1038/nature06177.

Geels, F.W., and J. Schot. 2007. Typology of sociotechnical transition pathways. Research Policy 36: 399-417. https://doi.org/ 10.1016/j.respol.2007.01.003.

Gibbons, L.V. 2020. Regenerative-The new sustainable? Sustainability 12: 5483. https://doi.org/10.3390/su12135483.

Gigliotti, L.C., M.R. Matchett, and D.S. Jachowski. 2019. Mountain lions on the prairie: Habitat selection by recolonizing mountain lions at the edge of their range. Restoration Ecology 27: 1032-1040. https://doi.org/10.1111/rec.12952.

Glasser, B.G., and A.L. Strauss. 2009. The discovery of grounded theory: Strategies for qualitative research. American Journal of Sociology. https://doi.org/10.1086/224572.

Goldblatt, A. 2011. Agriculture: Facts and Trends South Africa. World Wide Fund for Nature (WWF).

Gosnell, H., N. Gill, and M. Voyer. 2019. Transformational adaptation on the farm: Processes of change and persistence in transitions to 'climate-smart' regenerative agriculture. Global Environmental Change 59: 101965. https://doi.org/10.1016/j. gloenvcha.2019.101965.

Graham, K., A.P. Beckerman, and S. Thirgood. 2005. Human-predator-prey conflicts: Ecological correlates, prey losses and patterns of management. Biological Conservation 122: 159-171. https://doi.org/10.1016/j.biocon.2004.06.006.

Green, R.E., S.J. Cornell, J.P.W. Scharlemann, and A. Balmford. 2005. Farming and the fate of wild nature. Science 307: 550555. https://doi.org/10.1126/science.1106049.

Gunderson, L.H., and C.S. Holling. 2002. Panarchy: Understanding transformations in human and natural systems. Washington, DC: Island Press. https://doi.org/10.1016/j.ecolecon.2004.01. 010 .

Havstad, K.M., D.P.C. Peters, R. Skaggs, J. Brown, B. Bestelmeyer, E. Fredrickson, J. Herrick, and J. Wright. 2007. Ecological services to and from rangelands of the United States. Ecological Economics 64: 261-268. https://doi.org/10.1016/j.ecolecon.2007.08.005.

Head, B.W., and J. Alford. 2015. Wicked problems: Implications for public policy and management. Administration and Society 47: 711-739. https://doi.org/10.1177/0095399713481601.

IDFG. 2018. Commission Community Challenge Grant Announcement 2018. 
IDFG. 2020. Commission Community Challenge Grant Announcement 2020.

Ives, C.D., R. Freeth, and J. Fischer. 2020. Inside-out sustainability: The neglect of inner worlds. AMBIO 49: 208-217. https://doi. org/10.1007/s13280-019-01187-w.

Jacobs, B., C. Lee, S. Watson, S. Dunford, and A. Coutts-Smith. 2016. Adaptation planning process and government adaptation architecture support regional action on climate Change in New South Wales, Australia. In Climate change management, ed. W. Leal Filho, 17-29. Cham: Springer. https://doi.org/10.1007/ 978-3-319-25814-0_2.

Jacobs, B., D. Cordell, J. Chin, and H. Rowe. 2017. Towards phosphorus sustainability in North America: A model for transformational change. Environmental Science and Policy 77: 151-159. https://doi.org/10.1016/j.envsci.2017.08.009.

Johnson, C.N., and A.D. Wallach. 2016. The virtuous circle: Predatorfriendly farming and ecological restoration in Australia. Restoration Ecology 24: 821-826. https://doi.org/10.1111/rec.12396.

Kansky, R., M. Kidd, and A.T. Knight. 2016. A wildlife tolerance model and case study for understanding human wildlife conflicts. Biological Conservation 201: 137-145. https://doi.org/10.1016/j. biocon.2016.07.002.

Kendall, K.C., J.B. Stetz, J. Boulanger, A. MacLeod, and D. Paetkau. 2009. Demography and genetic structure of a recovering grizzly bear demography and genetic structure of a recovering grizzly bear population population. The Journal of Wildlife Management. https://doi.org/10.2193/2008-330.

Knapp, C.N., and M.E. Fernandez-Gimenez. 2009. Knowledge in practice: Documenting rancher local knowledge in Northwest Colorado. Rangeland Ecology and Management 62: 500-509. https://doi.org/10.2111/08-175.1.

Levin, K., B. Cashore, S. Bernstein, and G. Auld. 2012. Overcoming the tragedy of super wicked problems: Constraining our future selves to ameliorate global climate change. Policy Sciences 45: 123-152. https://doi.org/10.1007/s11077-012-9151-0.

Leys, A.J., and J.K. Vanclay. 2011. Social learning: A knowledge and capacity building approach for adaptive co-management of contested landscapes. Land Use Policy 28: 574-584. https://doi.org/ 10.1016/j.landusepol.2010.11.006.

Littin, K.E., and D.J. Mellor. 2005. Strategic animal welfare issues: Ethical and animal welfare issues arising from the killing of wildlife for disease control and environmental reasons. OIE Revue Scientifique Et Technique 24: 767-782. https://doi.org/ 10.20506/rst.24.2.1611.

Madden, F., and B. McQuinn. 2014. Conservation's blind spot: The case for conflict transformation in wildlife conservation. Biological Conservation 178: 97-106. https://doi.org/10.1016/j.biocon. 2014.07.015.

Maletzke, B.T., R.B. Wielgus, D.J. Pierce, D.A. Martorello, and D.W. Stinson. 2016. A meta-population model to predict occurrence and recovery of wolves. The Journal of Wildlife Management 80: 368-376. https://doi.org/10.1002/jwmg.1008.

Manfredo, M.J., T.L. Teel, and K.L. Henry. 2009. Linking society and environment: A multilevel model of shifting wildlife value orientations in the western United States. Social Science Quarterly 90: 407-427. https://doi.org/10.1111/j.1540-6237.2009.00624.x.

Manfredo, M.J., L. Sullivan, A.W. Don Carlos, A.M. Dietsch, T.L. Teel, A.D. Bright, and J. Bruskotter. 2018. America's wildlife values: The social context of Wildlife Management in the U.S. Fort Collins: Colorado State University, Department of Human Dimensions of Natural Resources.

Marchini, S., K.M.P.M.B. Ferraz, A. Zimmermann, T. Guimarães-Luiz, R. Morato, P.L.P. Correa, and D.W. Macdonald. 2019. Planning for coexistence in a complex human-dominated world. HumanWildlife Interactions. https://doi.org/10.1017/9781108235730. 022 .
McManus, J.S., A.J. Dickman, D. Gaynor, B.H. Smuts, and D.W. Macdonald. 2015. Dead or alive? Comparing costs and benefits of lethal and non-lethal human-wildlife conflict mitigation on livestock farms. Oryx 49: 687-695. https://doi.org/10.1017/ S0030605313001610.

McManus, J., S.A. Goets, W.J. Bond, J.R. Henschel, B. Smuts, and S.J. Milton. 2018. Effects of short-term intensive trampling on Karoo vegetation§. African Journal of Range and Forage Science 35: 311-318. https://doi.org/10.2989/10220119.2018. 1529706.

Mead, D., and L. Moseley. 2001. The use of the Delphi as a research approach. Nurse Researcher. https://doi.org/10.7748/nr2001. 07.8.4.4.c6162.

Naidoo, R., A. Balmford, R. Costanza, B. Fisher, R.E. Green, B. Lehner, T.R. Malcolm, and T.H. Ricketts. 2008. Global mapping of ecosystem services and conservation priorities. Proceedings of the National Academy of Sciences of the United States of America 105: 9495-9500. https://doi.org/10.1073/pnas.0707823105.

Nattrass, N., B. Conradie, J. Stephens, and M. Drouilly. 2020. Culling recolonizing mesopredators increases livestock losses: Evidence from the South African Karoo. AMBIO 49: 1222-1231. https:// doi.org/10.1007/s13280-019-01260-4.

Naughton-Treves, L., R. Grossberg, and A. Treves. 2003. Paying for tolerance: Rural citizens' attitudes toward wolf depredation and compensation. Conservation Biology 17: 1500-1511. https://doi. org/10.1111/j.1523-1739.2003.00060.x.

Norström, A.V., C. Cvitanovic, M.F. Löf, S. West, C. Wyborn, P. Balvanera, A.T. Bednarek, E.M. Bennett, et al. 2020. Principles for knowledge co-production in sustainability research. Nature Sustainability 3: 182-190. https://doi.org/10.1038/ s41893-019-0448-2.

O'Brien, K. 2018. Is the $1.5^{\circ} \mathrm{C}$ target possible? Exploring the three spheres of transformation. Current Opinion in Environmental Sustainability 31: 153-160. https://doi.org/10.1016/j.cosust. 2018.04.010

Ogada, M.O., R. Woodroffe, N.O. Oguge, and L. Frank. 2003. Limiting depredation by African carnivores: The role of livestock husbandry. Conservation Biology. https://doi.org/10.1111/j.15231739.2003.00061.x.

Oregon Department of Fish and Wildlife. 2014. Oregon wolf conservation and management plan. Oregon Administrative Rules 635: $1-9$.

Pahl-Wostl, C. 2002. Towards sustainability in the water sector-The importance of human actors and processes of social learning. Aquatic Sciences 64: 394.

Palmer, A.R., and J.E. Bennett. 2013. Degradation of communal rangelands in South Africa: Towards an improved understanding to inform policy understanding to inform policy. African Journal of Range \& Forage Science. https://doi.org/10.2989/10220119. 2013.779596.

Pannell, D.J., and F. Vanclay. 2011. Changing land management : Adoption of new practices by rural landholders. Melbourne: CSIRO Publishing.

Pannell, D., G. Marshall, N. Barr, A. Curtis, F. Vanclay, and R. Wilkinson. 2006. Understanding and promoting adoption of conservation practices by rural landholders. Australian Journal of Experimental Agriculture 46: 1407-1424. https://doi.org/10. 1071/EA05037.

Patterson, J., K. Schulz, J. Vervoort, C. Adler, M. Hurlbert, S. van der Hel, A. Schmidt, A. Barau, et al. 2015. "Transformations towards sustainability" Emerging approaches, critical reflections, and a research agenda. Lund and Amsterdam: Earth System Governance Project.

Patterson, J., K. Schulz, J. Vervoort, S. van der Hel, O. Widerberg, C. Adler, M. Hurlbert, K. Anderton, et al. 2017. Exploring the governance and politics of transformations towards 
sustainability. Environmental Innovation and Societal Transitions 24: 1-16. https://doi.org/10.1016/j.eist.2016.09.001.

Powell, C. 2002. Methodological issues in nursing research. The Delphi technique: Myths and realities. Journal of Advanced Nursing 41: 376.

Price, R.J., and R.B. Hacker. 2009. Grain \& Graze: An innovative triple bottom line approach to collaborative and multidisciplinary mixed-farming systems research, development and extension. Animal Production Science 49: 729-735. https://doi.org/10. 1071/EA08306.

Prowse, T.A.A., C.N. Johnson, P. Cassey, C.J.A. Bradshaw, and B.W. Brook. 2015. Ecological and economic benefits to cattle rangelands of restoring an apex predator. Journal of Applied Ecology 52: 455-466. https://doi.org/10.1111/1365-2664.12378.

Rickards, L., and S.M. Howden. 2012. Transformational adaptation: Agriculture and climate change. Crop and Pasture Science 63: 240-250. https://doi.org/10.1071/CP11172.

Ripple, W.J., J.A. Estes, R.L. Beschta, C.C. Wilmers, E.G. Ritchie, M. Hebblewhite, J. Berger, B. Elmhagen, et al. 2014. Status and ecological effects of the world's largest carnivores. Science. https://doi.org/10.1126/science.1241484.

Ripple, W.J., G. Chapron, J.V. López-Bao, S.M. Durant, D.W. MacDonald, P.A. Lindsey, E.L. Bennett, R.L. Beschta, et al. 2017. Conserving the world's megafauna and biodiversity: The fierce urgency of now. BioScience 67: 197-200. https://doi.org/10. 1093/biosci/biw168.

Rodela, R. 2011. Social learning and natural resource management: the emergence of three research perspectives. Ecology and Society 16 (4): 30. https://doi.org/10.5751/ES-04554-160430.

Rust, N., and L.L. Marker. 2013. Attitudes toward predators and conservancies among Namibian farmers. Human Dimensions of Wildlife 18: 463-468.

Saldana, J. 2009. Qualitative researcher's companion. Thousand Oaks: Sage Publications.

Santiago-Ávila, F.J., and W.S. Lynn. 2020. Bridging compassion and justice in conservation ethics. Biological Conservation. https:// doi.org/10.1016/j.biocon.2020.108648.

Schurch, M.P., J. Mcmanus, S. Goets, L.E. Pardo, D. Gaynor, I. Samuels, C. Cupido, V. Couldridge, et al. 2021. Wildlifefriendly livestock management promotes mammalian biodiversity recovery on a semi-arid Karoo farm in South Africa. Frontiers in Conservation Science. https://doi.org/10.3389/ fcosc. 2021.652415 .

Schwartz, C.C., M.A. Haroldson, K.A. Gunther, and D. Moody. 2001. Distribution of grizzly bears in the greater Yellowstone ecosystem, 1999-2000. Ursus 13: 203-212. https://doi.org/10. $2307 / 3873200$.

Sellberg, M.M., S.T. Borgström, A.V. Norström, and G.D. Peterson. 2017. Improving participatory resilience assessment by cross-fertilizing the resilience alliance and transition movement approaches. Ecology and Society. https://doi.org/10.5751/ ES-09051-220128.

Shivik, J.A., A. Treves, and P. Callahan. 2003. Nonlethal techniques for managing predation: Primary and secondary repellents. Conservation Biology 17: 1531-1537.

Slagle, K., R. Zajac, J. Bruskotter, R. Wilson, and S. Prange. 2013. Building tolerance for bears: A communications experiment. Journal of Wildlife Management 77: 863-869. https://doi.org/ 10.1002/jwmg.515.

Spencer, K., M. Sambrook, S. Bremner-Harrison, D. Cilliers, R.W. Yarnell, R. Brummer, and K. Whitehouse-Tedd. 2020. Livestock guarding dogs enable human-carnivore coexistence: First evidence of equivalent carnivore occupancy on guarded and unguarded farms. Biological Conservation 241: 108256. https://doi.org/10.1016/j.biocon.2019.108256.
Stern, M.J. 2018. Social science theory for environmental sustainability: A practical guide. Oxford: Oxford University Press. https://doi.org/10.1093/oso/9780198793182.001.0001.

Stone, S.A., S.W. Breck, J. Timberlake, P.M. Haswell, F. Najera, B.S. Bean, and D.J. Thornhill. 2017. Adaptive use of nonlethal strategies for minimizing Wolf-sheep conflict in Idaho. Journal of Mammalogy 98: 33-44. https://doi.org/10.1093/jmammal/ gyw188.

Swanepoel, L.H., P. Lindsey, M.J. Somers, W. van Hoven, and F. Dalerum. 2013. Extent and fragmentation of suitable leopard habitat in South Africa. Animal Conservation 16: 41-50. https://doi.org/10.1111/j.1469-1795.2012.00566.x.

The Resilience Alliance. 2010. Assessing resilience in social-ecological systems: Workbook for practitioners. Halifax: Resilience Alliance.

Treves, A., and J. Bruskotter. 2014. Tolerance for predatory wildlife. Science 344: 476-477. https://doi.org/10.1126/science.12526 90.

Treves, A., M. Krofel, and J. McManus. 2016. Predator control should not be a shot in the dark. Frontiers in Ecology and the Environment 14: 380-388. https://doi.org/10.1002/fee.1312.

Van Eeden, L. 2020. Exploring nationality and social identity to explain attitudes toward conservation actions in the United States and Australia. Conservation Biology. https://doi.org/ 10.1111/cobi.13488.

Van Bommel, L., and C.N. Johnson. 2012. Good dog! Using livestock guardian dogs to protect livestock from predators in Australia's extensive grazing systems. Wildlife Research 39: 220-229. https://doi.org/10.1071/WR11135.

Van Den Bergh, J.C.J.M., B. Truffer, and G. Kallis. 2011. Environmental innovation and societal transitions: Introduction and overview. Environmental Innovation and Societal Transitions 1: 1-23. https://doi.org/10.1016/j.eist.2011.04.010.

van Eeden, L.M., A. Eklund, J.R.B. Miller, J.V. López-Bao, G. Chapron, M.R. Cejtin, M.S. Crowther, C.R. Dickman, et al. 2018a. Carnivore conservation needs evidence-based livestock protection. PLoS Biology 16: 1-8. https://doi.org/10.1371/ journal.pbio.2005577.

van Eeden, L.M., M.S. Crowther, C.R. Dickman, D.W. Macdonald, W.J. Ripple, E.G. Ritchie, and T.M. Newsome. 2018b. Managing conflict between large carnivores and livestock. Conservation Biology. https://doi.org/10.1111/cobi.12959.

van Vuuren, D.P., N. Nakicenovic, K. Riahi, A. Brew-Hammond, D. Kammen, V. Modi, M. Nilsson, and K.R. Smith. 2012. An energy vision: The transformation towards sustainability-interconnected challenges and solutions. Current Opinion in Environmental Sustainability 4: 18-34. https://doi.org/10.1016/j. cosust.2012.01.004.

Walker, B., and D. Salt. 2006. Resilience thinking : Sustaining ecosystems and people in a changing world. Washington, DC: Island Press.

Wallach, A.D., D. Ramp, and A.J. O'Neill. 2017. Cattle mortality on a predator-friendly station in central Australia. Journal of Mammalogy 98: 45-52. https://doi.org/10.1093/jmammal/ gyw156.

Waudby, H.P., B.P. Smith, G.M. Robinson, S. Petit, and G. Earl. 2020. Applying a social-ecological system framework to diagnose drivers of dingo management practices. Australian Zoologist. https://doi.org/10.7882/az.2020.036.

White, C. 2012. Revolution on the range: The rise of a New Ranch in the American West. Washington, DC: Island Press Shearwater Books.

Wilson, S.M., M.J. Madel, D.J. Mattson, J.M. Graham, J.A. Burchfield, and J.M. Belsky. 2005. Natural landscape features, human-related attractants, and conflict hotspots: A spatial 
analysis of human-grizzly bear conflicts. Ursus 16: 117-129. https://doi.org/10.2192/1537-6176.

Woodroffe, R., and Frank, L. 2005. Lethal control of African lions (Panthera leo): local and regional population impacts. Animal Conservation. The Zoological Society of London. https://doi. org/10.1017/S1367943004001829

Woodroffe, R., and J.R. Ginsberg. 1998. Edge effects and extinction of populations inside protected areas. Science 280: 2126

Young, J.K., J. Steuber, A. Few, A. Baca, and Z. Strong. 2019. When strange bedfellows go all in: A template for implementing nonlethal strategies aimed at reducing carnivore predation of livestock. Animal Conservation 22: 207-209. https://doi.org/10. 1111/acv.12453.

Publisher's Note Springer Nature remains neutral with regard to jurisdictional claims in published maps and institutional affiliations.

Louise Boronyak is a Doctoral candidate at the Institute for Sustainable Futures, University of Technology Sydney. She is the International Projects Liaison at the new International Wildlife Coexistence Network (IWCN). Her research focusses on identifying holistic, compassionate and integrative approaches to coexist with wildlife and support local communities. Her interdisciplinary research spans social science, natural resource management, climate adaptation, animal welfare and conservation sciences.

Dr. Brent Jacobs is an Associate Professor at the Institute for Sustainable Futures, University of Technology Sydney. Brent's background is in agricultural science with broad experience in agricultural systems and eco-physiology of crops and pastures. His current research interests include: resilience, vulnerability and adaptive capacity of communities and Social- Ecological Systems to climate change and food security.

Dr. Arian Wallach is a Lecturer, School of Life Sciences at the Centre for Compassionate University of Technology Sydney. Her research interests include the ecological role of large predators on biodiversity and functioning of novel ecosystems. Arian's fieldwork is mainly conducted across the Australian arid zone, where she researches the influence of dingoes on biodiversity and native-non-native coexistence.

Dr. Jeannine McManus is the Field Manager at the Landmark Foundation. She undertakes research into leopard ecology and their population density with a particular focus on establishing landscape connectivity in the Eastern and Western Cape. During her time on the project she has proudly assisted in converting over 170000 ha of privately owned land with participating farmers into biodiversity friendly corridors.

Suzanne Stone is a coexistence practitioner and has been on the front lines of wolf restoration in the Western USA since 1988. Suzanne has worked closely with agency wildlife managers, ranchers, wolf conservationists, and community members to demonstrate that nonlethal methods to build coexistence between wolves and ranching operations are more effective at protecting livestock and ensuring the wolf's valuable role in the wild. She cofounded the Wood River Wolf Project in Blaine County, Idaho. She has shared her expertise in Germany, Israel, Australia in relation to nonlethal tools for wolves and other species.

Shane Stevenson is a rancher from Idaho that consults on nonlethal solutions to human-carnivore conflict in livestock industries. He currently works on a ranch in Oregon to create habitat for wild birds.

Dr. Bool Smuts is the Director of the Landmark Foundation. Bool is a sustainable development expert, with environmental management, socio-economic development and environmental auditing and risk management expertise. He has special interests in renewable energies, protected areas development and management, tourism, species conservation, resource utilisation, and related conservation economy development.

Hilary Zaranek is wildlife biologist and rancher based in Montana. In 2013, she cofounded the Tom Miner Basin Association with her sister in law, Malou Anderson. The Association's work centers around supporting shared landscapes, conflict prevention, and preserving the positive traditions of the rural way of life by enhancing rural community support and connectedness. 


\section{Terms and Conditions}

Springer Nature journal content, brought to you courtesy of Springer Nature Customer Service Center GmbH ("Springer Nature").

Springer Nature supports a reasonable amount of sharing of research papers by authors, subscribers and authorised users ("Users"), for smallscale personal, non-commercial use provided that all copyright, trade and service marks and other proprietary notices are maintained. By accessing, sharing, receiving or otherwise using the Springer Nature journal content you agree to these terms of use ("Terms"). For these purposes, Springer Nature considers academic use (by researchers and students) to be non-commercial.

These Terms are supplementary and will apply in addition to any applicable website terms and conditions, a relevant site licence or a personal subscription. These Terms will prevail over any conflict or ambiguity with regards to the relevant terms, a site licence or a personal subscription (to the extent of the conflict or ambiguity only). For Creative Commons-licensed articles, the terms of the Creative Commons license used will apply.

We collect and use personal data to provide access to the Springer Nature journal content. We may also use these personal data internally within ResearchGate and Springer Nature and as agreed share it, in an anonymised way, for purposes of tracking, analysis and reporting. We will not otherwise disclose your personal data outside the ResearchGate or the Springer Nature group of companies unless we have your permission as detailed in the Privacy Policy.

While Users may use the Springer Nature journal content for small scale, personal non-commercial use, it is important to note that Users may not:

1. use such content for the purpose of providing other users with access on a regular or large scale basis or as a means to circumvent access control;

2. use such content where to do so would be considered a criminal or statutory offence in any jurisdiction, or gives rise to civil liability, or is otherwise unlawful;

3. falsely or misleadingly imply or suggest endorsement, approval, sponsorship, or association unless explicitly agreed to by Springer Nature in writing;

4. use bots or other automated methods to access the content or redirect messages

5. override any security feature or exclusionary protocol; or

6. share the content in order to create substitute for Springer Nature products or services or a systematic database of Springer Nature journal content.

In line with the restriction against commercial use, Springer Nature does not permit the creation of a product or service that creates revenue, royalties, rent or income from our content or its inclusion as part of a paid for service or for other commercial gain. Springer Nature journal content cannot be used for inter-library loans and librarians may not upload Springer Nature journal content on a large scale into their, or any other, institutional repository.

These terms of use are reviewed regularly and may be amended at any time. Springer Nature is not obligated to publish any information or content on this website and may remove it or features or functionality at our sole discretion, at any time with or without notice. Springer Nature may revoke this licence to you at any time and remove access to any copies of the Springer Nature journal content which have been saved.

To the fullest extent permitted by law, Springer Nature makes no warranties, representations or guarantees to Users, either express or implied with respect to the Springer nature journal content and all parties disclaim and waive any implied warranties or warranties imposed by law, including merchantability or fitness for any particular purpose.

Please note that these rights do not automatically extend to content, data or other material published by Springer Nature that may be licensed from third parties.

If you would like to use or distribute our Springer Nature journal content to a wider audience or on a regular basis or in any other manner not expressly permitted by these Terms, please contact Springer Nature at

onlineservice@springernature.com 